\title{
Administrative Turbulence: Origins of the Origin
}

\author{
Thanawat Pimoljinda $^{1}$, Ritthikorn Siriprasertchok ${ }^{1}$, Sunee Hongwiset ${ }^{1}$ \\ ${ }^{1}$ Graduate School of Public Administration, Burapha University, Thailand
}

\begin{abstract}
This article focuses on the origins of administrative turbulence, especially in the face of non-linear dynamic change of current socio-economic conditions. An argument made by this article is that the key parameter catalyzing such turbulence results mainly from the interaction between the government's decision-making and the utilization of academic disciplines. Under the surface of this is that an interdisciplinary approach to policy decision-making and administration is applied only when such disciplines can contribute to the government's policy discourses on economic development projects, and thereby leaving behind equilibrium of development and sustainability. Also involved is the divergence among academic disciplines in contributing to the government's policy design and decisionmaking process, mostly caused by the unconformity of their principles and methods.
\end{abstract}

Keywords: Administrative Turbulence, Public Policy, Non-linear Dynamic Changes, Interdisciplinary Approach

\section{Introduction}

A challenge to the current public administration in the age of global interdependence is unpredictable situations and their impacts caused by non-linear dynamic changes of socio-economic conditions at both the national and international levels. Such circumstances are generally described in academic and professional communities as the time of turbulence where things are increasingly complicated. This is, of course, challenging the wisdom of governments and public administrators accordingly (see Nargesian, Esfahani, \& Rajabzadeh, 2010; Rutgers, 2010; Walker, 2011; Gulrajani \& Moloney, 2012).

However, not only does administrative turbulence result from the complexity of socioeconomic development, a key parameter catalyzing such turbulence is also triggered by government decisions. This article commences with an argument that the ways in which governments decide and act in bolstering economic growth and competitiveness through national economic development projects are regarded as having more influence on such administrative turbulence, and have made the situations more dynamic and uncertain. It resulted neither from government reform programs nor the paradigmatic change of administrative principles, but the root of administrative turbulence is the incompatibilities between the theoretical contributions of academic scholars and the pragmatic consideration and decision-making made by the government.

In clarifying the above context, this article starts by focusing on the origins of administrative turbulence. An overview regarding the features of turbulence on public administration is addressed. The limits and constraints on government decision-making which may lead to administrative turbulence are then discussed, as well as the role of the academic community in contributing to the government's decision-making process is also provided. Debates and a conclusion are then accordingly provided for raising key points 
regarding the [in]consistency between theoretical principles and practical reasons.

\section{Origins of the Origin}

In a broad sense, the term 'turbulence' can be interpreted as, if not natural disaster, either intentionally or unintentionally human-made situations. It is usually realized in the form of changes (Holsti, 1998; Melchor, 2008; Walker, 2011), which either suddenly take place or gradually emerge, and thereby lead to uncertainty (Kiel, 2001). Uncertain change is, at the same time, an unpredictable circumstance which has been instigated by the people, and affects the people themselves. Nevertheless, changes are not linear or systemic as they had been in the past. Rather, socio-economic development conditions today are more complex and non-equilibrium in nature (Farazmand, 2003). The simplest reason is that the impacts which stem from either economic or social issues in a given country will have spill-over effects both on each other and on other parts of the world. It may simultaneously make the domestic situations in other countries change and uncontrollable accordingly.

Under the surface, these circumstances are caused by the government's decisions. As in the argument provided earlier, these decisions sometimes led to administrative turbulence as the policy analyses were always grounded in factual ignorance, and in some cases were denying the principles of must-be-related disciplines. Juxtaposing this argument to most government's decision-making today, it could be said that academic principles, methods, and tools applied to policy analysis are limited, and guided mainly by political objectives (see Ostrom, 2007; Walker, 2011; Dovers, 2005; Gulrajani and Moloney, 2012).

As we may observe, politics is not stable unless the economy is prospering. The knowledge and principles that can contribute to such a stage of development will customarily be drawn into pragmatic consideration, leaving aside other disciplines that may not be important for the realization of economic development. Especially in such a globalized economic system which is arguably illustrated as a non-equilibrium system, the government's decision-making on economic competitiveness and competition in many cases have a farreaching impact on sustainable development, placing the other parts of the system at risk (McNeill, Garcia-Godos, \& Gjerdaker, 2001; Dernbach, 2011).

According to the origins of turbulence discussed above, analytical dimensions in the next two sections are focused firstly on the decision-making of the government that provokes a state of non-equilibrium development and brings about administrative turbulence. Second, the role of academic communities toward the balance of development and sustainability are addressed.

\section{Political Objective versus Interdisciplinary Approach}

In general, knowledge in both scientific and social spheres evolves over time. In part, this evolution emanates from an attempt to solve problems which are taking place in the social world, while some other aspects are developed in the form of futuristic studies in order to provide a springboard for future strategic socio-economic development or ecological sustainability. As Ostrom (2007), Putra (2009), Meek (2010), Walker (2011) and some other scholars suggested, administrative science is a design science, applying appropriate methods and tools from two or more disciplines aiming at coping with the context of non-linear dynamic change resulting from complexity and uncertainty of socio-economic development. Encompassing other fields of knowledge in the study of real world issues is a fundamental characteristic of public administration, universally recognized as an interdisciplinary study. The aim of this is to respond to the 
problems taking place within a government's jurisdiction at all levels (Melchor, 2008; Rutgers, 2010).

However, in most cases, even if the concepts of nonlinearity, chaos and complexity are increasingly and widely discussed in the academic and professional spheres, a pragmatic concern regarding an interdisciplinary approach to policy analysis or administration in the scope of government action is rarely addressed. Sometimes this may just appear in the manner of rhetorical statements. Some explicit examples are that of airports built on man-made islands or dams which have led to disputes between the government and society, on the one hand, and are debated among environmentalists and ecologists, on the other. To achieve such mega-projects in economic infrastructure development or even overcoming natural obstacles, theoretical principles of the physical geography, environment and ecology may be less important than the sophisticated knowledge and techniques contributed by architecture and engineering (see Martin, 2001; Murphy, 2006).

As frequently discussed in political science, the scope of policy decision-making is always limited to political power, even if the reinventing of government concepts are increasingly manipulated in governmental reform programs as Osborne and Gaebler (1992); Hughes (2003, pp.71-93), Denhardt \& Denhardt (2007, pp.10-19) and other scholars have suggested. Meanwhile, the influence of political power is typically reflected in terms of the economic intervention and operation of public administrators which must be in line with the government's policies (Cochran \& Malone, 2005, 29-35). Therefore, from a realist's point of view, public policy which is designed in response to social problems is implicitly a device of the governments to keep their power in hand, or at least to gain support from the constituency. This seemingly goes against a dictum of Woodrow Wilson (1887) which states; "administration lies outside the proper sphere of politics; and administrative questions are not political questions" (see Denhardt \& Grubbs, 2003; Rutgers, 2010).

\section{Academic Disciplines in Compatibilities}

Not only is the administrative sphere criticized as a catalyst of administrative turbulence, but also academic communities and the matter of their disciplines and methodologies sometimes provide divergent proposals opposing one another (McNeill, Garcia-Godos and Gjerdaker, 2001). As we have seen in regard to the economic gap, social problems, environmental degradation, climate change, and some other human-made problems, these both implicitly and explicitly reflect a pitfall of policy design resulting from decisions on rapid economic development without comprehensive deliberation on side-effect impacts.

Perhaps, since the publication of Adam Smith's Wealth of Nations in 1779, economics has increasingly become a basic foundation for national economic prosperity, founded on the basis of well-being of the people together with the free market mechanism (see Cochran \& Malone, 2005). Related to these, as mentioned earlier, are the administrative reforms aimed at enhancing the efficiency and effectiveness of the existing state apparatus for the purpose of international comparative advantage (Farazmand, 2003; Hughes, 2003, 50-51; Denhardt \& Denhardt, 2007, 42-43; Ostrom, 2007).

In a general sense, economic growth and competitiveness are built upon various development projects, using different principles and methods for a specific purpose. Nevertheless, as discussed earlier, suchlike will be made use of for such a project only if their proposed principles and methods can respond to project's goal. As McNeill, Garcia-Godos and Gjerdaker (2001, 21-23) discussed in their research, the basic perspective regarding 
knowledge applicable for decision-making depends mainly on the nature of the issue. Together with this is questions of which disciplines, and to what extent they must contribute to, the government's policy design and decision-making process and public administration.

Initially, many scholars insisted that economics is one discipline that has most influenced policy making (McNeill, GarciaGodos and Gjerdaker, 2001, 47; Ostrom, 2007; Kim, 2008), conforming to a new phase of the current global economy. Under the surface of this statement is mirrored a situation that some other natural and social scientists and their research, which are devoted to the promotion of balanced and sustainable development, are leaving behind. It can be inferred from the arguments mentioned above that academic knowledge application for national economic development is limited to a few disciplines that can contribute to decision-making process. Such a process has thus often become a key factor in overshadowing the balanced and sustainable development concepts provided by many scholars from other disciplines.

As we may observe, in the world of economic competition, economics, which is a field of study in social science - aimed mainly at social well-being -firstly requires scientific knowledge like innovative technology, engineering and architecture for its purpose. The well-being and socio-cultural changes which are based on sociology or anthropology, or even sustainable ecological and environmental systems, always come later as they are concerned less with, and not closely related to, the enhancement of national economy and competitiveness.

\section{Conclusion}

As discussed in this article, we can see a pitfall for government decision-making which is exposed in the form of contradictory principles between economic growth and sustainable development on the one hand, and the role of the academic community in contributing their knowledge and principles to the government's development projects on the other. Even if these may not have a direct impact on administrative turbulence, they do have a far-reaching impact indirectly on the long term.

\section{References}

[1] Cochran, C. L., \& Malone, E. F. Public Policy: Perspectives and Choices (3rd ed.). London: Lynne Rienner, 2005.

[2] Denhardt, J. V., \& Denhardt, R. B. The new public service: Serving, not steering. Armonk, NY: M.E. Sharpe, 2007.

[3] Denhardt, R. B., \& Grubbs, J. W. Public administration: An action orientation (4th ed.). Belmont, CA: Thomson Wadsworth, 2003.

[4] Dernbach, J. C. Creating the law of environmentally sustainable economic development. Pace Environmental Law Review, 2011, 28 (3): 613-641.

[5] Dovers, S. Clarifying the imperative of integration research for sustainable environmental management. Journal of Research Practice, 2005, 1 (2): 1-19.

[6] Farazmand, A. Chaos and transformation theories: A theoretical analysis with implications for organization theory and public management. Public Organization Review, 339-372.

[7] Gulrajani, N., \& Moloney, K. (2012). Globalizing public administration: Today's research and tomorrow's agenda. Public Administration Review, 2012, 72 (1): 7886.

[8] Haque, M. S. Theory and practice of public administration in Southeast Asia: Traditions, Directions, and Impacts. International Journal of Public Administration, 2007, 30: 1297-1326.

[9] Holsti, K. J. The problem of change in international relations theory (Working Paper No. 26). The University of British Columbia: Institute of International Relations, 1998.

[10] Hughes, O. E. Public management and administration: An introduction (3rd ed.). New York: Palgrave Macmillan, 2003. 
[11] Kiel, L. D. The evolution of nonlinear dynamics in political science and public administration: Methods, modeling and momentum. Discrete Dynamic in Nature and Society, 2001, 5: 265-279.

[12] Kim, C. K. Public Administration in the Age of Globalization. International Public Management Review, 2008, 9 (1): 39-55.

[13] Martin, R. Geography and public policy: The case of the missing agenda. Progress in Human Geography, 2001, 25 (2): 189210.

[14] McNeill, D., Garcia-Godos, J., \& Gjerdaker, A. Interdisciplinary research on development and the environment (SUM Report No.10). Oslo: University of Oslo, Center for Development and the Environment, 2001.

[15] Meek, J. W. Complexity theory for public administration and policy. Emergence: Complexity \& Organization, 2010, 12 (1): 1-4.

[16] Melchor, O. H. Managing change in OECD governments: An introductory framework (Working Papers on Public Governance No. 12) France: OECD publishing, 2008.

[17] Murphy, A. B. Enhancing geography's role in public debate. Annals of the Association of American Geographers, 2006, 96 (1): 1-13.

[18] Nargesian, A., Esfahani, S. A., \& Rajabzadeh, A. A quasi paradigmic view to the public administration evolution. European Journal of Social Science, 2010, 15 (2): 241-249.
[19] Osborne, D., \& Gaebler, T. Reinventing government: How the entrepreneurial spirit is transforming the public sector. Reading, MA: Addison-Wesley, 1992.

[20] Ostrom, E. Challenges and growth: The development of the interdisciplinary field of institutional analysis. Journal of Institutional Economics, 2007, 3 (3): 239264.

[21] Putra, F. Crisis management in public administration. Planning Forum, 2009, 13 (14): 152-177.

[22] Rutgers, M. Theory and Scope of Public Administration: An Introduction to the State's Epistemology. Amsterdam: University of Amsterdam, 2010.

[23] Walker, R. M. Globalized public management: An interdisciplinary design science? Journal of Public Administration Research and Theory, 2011] 21: 53-59.

[24] Wilson, W. The Study of Administration. Political Science Quarterly, 1887, 2 (2): 197-222. 